\title{
Clinical Applications of Saffron (Crocus sativus) and its Constituents: A Review
}

Authors

Affiliations
M. Moshiri ${ }^{1}$, M. Vahabzadeh ${ }^{1,2}$, H. Hosseinzadeh ${ }^{3}$

Department of Pharmacodynamy and Toxicology, School of Pharmacy, Mashhad University of Medical Sciences, Mashhad, IR. Iran

${ }^{2}$ Medical Toxicology Research Centre, Faculty of Medicine, Mashhad University of Medical Sciences, Mashhad, Iran

${ }^{3}$ Pharmaceutical Research Center, Department of Pharmacodynamy and Toxicology, School of Pharmacy,

Mashhad University of Medical Sciences, Mashhad, Iran

Key words
Crocus sativus
clinical
saffron
crocin
safranal

received 11.11.2013 accepted 21.02.2014

\section{Bibliography}

DOI http://dx.doi.org/

10.1055/s-0034-1375681

Published online:

May 21, 2014

Drug Res 2015;

65: 287-295

(c) Georg Thieme Verlag KG

Stuttgart · New York

ISSN 2194-9379

\section{Correspondence}

\section{H. Hosseinzadeh}

Department of Pharmaco-

dynamy and Toxicology

Pharmaceutical Research

Center

School of Pharmacy

Mashhad University of Medical

Sciences

P.O. Box 917751365

Mashhad

Iran

Tel.: + 98/511/8819 042

Fax: +98/511/8823 251

hosseinzadehh@mums.ac.ir

\section{Abstract}

$\nabla$

Commonly known as saffron, Crocus sativus L and its active components have shown several useful pharmacological effects such as anticonvulsant, antidepressant, anti-inflammatory, antitumor, radical scavenger effects, learning and memory improving effects, etc. There has been an increasing body of data on saffron use in medical databases within the last 20 years. In the current review, the strengths and weaknesses of some of the clinical trials about different pharmacological effects of saffron will be discussed C. sativus extract has been studied in 8 antidepressant clinical trials in comparison to placebo or some antidepressant drugs, in which saffron showed effectiveness as an antidepressant drug. Clinical trials on anti-Alzheimer effect

\section{Introduction}

$\nabla$

Crocus sativus L (commonly known as saffron) is a perennial stemless herb from the Iridaceae family that is largely cultivated in Iran and some other countries including Spain, India and Greece [1]. C. sativus grows up to $20-30 \mathrm{~cm}$ height and has 5-11 true leaves that are shielded and covered by 5-11 non-photosynthetic and white leaves (cataphylls). In October, the plant blooms striped purple with a honey-like smell [2].

Important constituents of saffron that are pharmacologically active are bitter principles (e.g. picrocrocin), volatile agents (e.g. safranal), and dye materials (e.g. crocetin and its glycoside crocin) [1].

Although research into effects of saffron is not a new subject and ancient Persian literatures recommend using saffron as a medicine for treating several diseases, the number of cited documents in medical databases such as Scopus ${ }^{\circledR}$ have increased over the last 20 years, most of them (78.51\%) being original research. Furthermore, of saffron demonstrated that it was more effective than the placebo, and as effective as donepezil. 2 clinical trials on antipruritic and complexion promoter in skin care effects of saffron both confirmed that saffron was more efficient than the placebo. In another clinical trial, it was proved that in addition to the weight loss treatment, saffron could reduce snacking frequency. Clinical trials conducted on women with premenstrual syndrome showed that saffron could reduce suffering symptoms more than the placebo and similar to standard treatments.

Furthermore, additional clinical trials on effects of saffron on erection dysfunction, allergies, cardiovascular and immune system as well as its safety, toxicity and human pharmacokinetics are reviewed herein.

the first record being cited with the keywords of "saffron + clinical trial" in Scopus ${ }^{\circledR}$ belongs to the publications of 1998. The number of such papers has been increased through 2004-2012, 62\% of which being original clinical trials (32 papers). However, 66 countries were cited for the authors' affiliations of the cited documents in Scopus ${ }^{\circledR}$ with the keyword "saffron". Most articles were published by the Iranian and Spanish researchers ( $22.3 \%$ by Iranian and $10.7 \%$ by Spanish authors) and more than one-third of the clinical trials were documented by the Iranian scientists (37.3\%).

Several useful pharmacological effects of saffron or its active components have been shown in animal studies along with the few clinical trials, including: anticonvulsant $[3,4]$, antidepressant $[5,6]$, anti-inflammatory $[7,8]$, antitumor [9], radical scavenger effects [10] and learning and memory improving [11-13]. Protective effects of saffron extracts on goenotxins-induced oxidative stress have been reported $[14,15]$. There are numerous studies about antioxidant effects of 
saffron or its ingredients $[12,16,17]$. It has been also shown that saffron can promote the diffusivity of oxygen in different tissues [17]. A number of investigations into safety and toxicity of saffron and its components have been conducted [18-21] and some clinical trials about different pharmacological effects of saffron can be found in literatures. In this review, we have discussed strengths and weaknesses of the aforementioned studies.

\section{Pharmacokinetics}

$\nabla$

Pharmacokinetic evaluation of crocin and crocetin has been carried out in animal and human studies. Pharmacokinetic study of crocin, an active compound of saffron, in mice showed that it could not be absorbed through the gastrointestinal tract after either a single dose or repeated doses [22]. Crocin was largely excreted from the intestinal tract following oral administration [23]. It is hydrolyzed to crocetin before absorption through gastro-intestinal tract $[22,24]$.

Crocetin is quickly absorbed after oral administration to mice. It can be detected in plasma in free form as well as in the form of a glucuronic acid conjugate [22]. In rats, a single oral dose of $50 \mathrm{mg} / \mathrm{kg}$ crocetin has been shown to have $t 1 / 2=30 \pm 6 \mathrm{~min}$, $\mathrm{t}_{\max }=65 \pm 16 \mathrm{~min}, \mathrm{C}_{\max }=5.0 \pm 1.0 \mu \mathrm{g} / \mathrm{ml}, \mathrm{AUC}=845 \pm 109 \mu \mathrm{g} \times \mathrm{min} /$ $\mathrm{ml}$, and $\mathrm{Vd}=5.0 \pm 0.8 \mathrm{l} / \mathrm{kg}$ [23]. The short plasma half-life of crocetin results in rapid elimination without being accumulated in the body $[23,25]$. Crocetin concentrations in rats' plasma did not tend to accumulate with the repeated doses of oral crocin $[23,24]$. The concentration-time curve of crocetin has been fitted with a 2-compartment open model after intravenous administration to rabbit [26].

Umigai and colleagues investigated pharmacokinetic profile of crocetin in healthy adult volunteers ( 5 men and 5 women) in an open-label, single dose escalation study [27]. Every individual consumed a single dose of crocetin at 3 doses (7.5, 15 and $22.5 \mathrm{mg}$ ) with one week intervals. Crocetin was rapidly absorbed in animal studies as well, and could be detected within an hour of administration, reaching to the maximum concentration in 4.0-4.8 h $\left(\mathrm{T}_{\max }\right)$ [27]. Additional important pharmacokinetic parameters of crocetin were as follows: $C_{\max }=100.9-279.7$ $\mathrm{ng} / \mathrm{ml}, \quad \mathrm{AUC}_{0-24 \mathrm{~h}}=556.5-1720.8 \mathrm{ng} \cdot \mathrm{h} / \mathrm{ml}, \mathrm{T}_{1 / 2}(\mathrm{~h})=6.1 \pm 7.2$ to $7.5 \pm 2.8, \mathrm{CL} / \mathrm{F}(\mathrm{l} / \mathrm{h})=12.8 \pm 2.9$ to $13.8 \pm 5.4$ and $\mathrm{Vd} / \mathrm{F}(\mathrm{l})=82.8 \pm 59.0$ to $152.6 \pm 80.1$ [27]. These parameters had no significant disparity in different doses, except for $C_{\max }$ and $A C_{0-24 h}$, which showed a dose dependent correlation [27].

\section{Safety and Toxicity \\ $\nabla$}

Saffron is being used as a food additive for several centuries and this supports its safety for most people. Administrated as medicine, saffron toxicity and safety required an evaluation.

Intraperitoneal $L_{50}$ values of saffron stigma and petal are reported to be 1.6 and $6 \mathrm{~g} / \mathrm{kg}$ in mice, respectively [28]. Nevertheless, it is not toxic when administrated orally with $\mathrm{LD}_{50}$ value being above $5000 \mathrm{mg} / \mathrm{kg}$. [19]. Although ingestion of less than $1.5 \mathrm{~g}$ of saffron is nontoxic for human [1], it is considered toxic when ingested with doses more than $5 \mathrm{~g}$ and could be lethal if taken about $20 \mathrm{~g} /$ day $[1,29]$. Given that the common effective doses being applied in clinical trials are considerably lower than this level (30-50 mg/day), saffron has a wide therapeutic index.
Mild toxicity with saffron induce dizziness, nausea, vomiting and diarrhea while a more severe toxicity can cause numbness, tingling in the hands and feet, and yellowish skin and eyes due to precipitation of yellow pigments on the skin and conjunctiva. Spontaneous bleeding may be a symptom as well [28,30,31].

A randomized, double-blind, placebo-controlled clinical trial (RDBPCCT) study by Mansoori et al. [18] evaluated the safety of saffron administration on sexual dysfunction in 20 adult patients suffering from major depressive disorder (MDD). The individuals were divided into 2 groups receiving either $15 \mathrm{mg}$ capsules of saffron or placebo twice daily. Laboratory tests including liver and renal function tests, blood cell count and coagulation tests, were assessed once before the trial and then in 4 weeks. No major laboratory changes were observed in patients receiving saffron, providing evidences for the safety of this herbal medicine [18].

Mohamadpour and colleagues, designed a RDBPCCT for safety of crocin tablets $(20 \mathrm{mg})$ in 22 men and women during 1 month [32]. Also, Modaghegh et al. have evaluated the safety of taking $200-400 \mathrm{mg}$ tablets of ethanolic extraction of saffron, nearly 4-10 times higher than the recommended therapeutic doses, for 1 week in a RDBPCCT on 30 healthy adults with normal appearance [28]. Saffron did not show any considerable adverse effects on blood pressure except for decreasing the standing systolic blood pressure and mean blood pressure. They reported no changes in the EKG of the participants [28]. Neither saffron nor crocin have had any dose-dependent effect on reducing RBC parameters $[28,32]$.

Saffron has been shown to reduce platelet counts at dose of $200 \mathrm{mg} /$ day [28]. However, in 2 different studies, Mansoori et al. and Mohamadpour et al., showed a non-significant reduction in such parameters $[18,32]$. In animal models, saffron was able to increase coagulation time in mice, and inhibit platelets aggregation in rabbit. These effects of saffron seem to be not related to crocin and safranal, but to adenosine $[28,33]$. Crocin tablets could have significantly reduced partial tromboplastin time but had no significant effect on prothrombin time [32].

However, crocin in subchronic administration in animal models is shown to reduce levels of serum total cholesterol, triglyceride and low-density lipoprotein cholesterol; inhibit the formation of aortic plaque and have anti-atherosclerosis effect due to antioxidant properties $[34,35]$. There was no change in the lipid profile of individuals ingesting saffron in Modaghegh et al. study [28]. Mohamadpour also reported insignificant changes in lipid profile of patients who were treated with crocin in comparison with control [32]. Nevertheless, diet programs of groups in the 2 mentioned studies did not match.

Administration of 200 and $400 \mathrm{mg} /$ day of saffron for 1 week elevated creatinine ( $\mathrm{Cr}$ ) and blood urea nitrogen (BUN) levels [28]. However, Mansoori et al. did not report any changes in the renal parameters 4 weeks following the ingestion of $30 \mathrm{mg} /$ day of ethanolic extract of saffron, and so did Mohamadpour et al. [18,32]. This difference seems to be related to the dose and the sampling time. Renal toxicity of saffron has also been mentioned in traditional medicine [18]. Mohajeri et al. reported that the intraperitoneal administration of the ethanolic extract of saffron to rats in doses of $0.35,0.70$ and $1.05 \mathrm{~g} / \mathrm{kg}$ BW for 2 weeks, significantly increased levels of BUN and $\mathrm{Cr}$ [21]. In 2 studies by Mohammadpour and Mansoori, clearance of $\mathrm{Cr}$ or more accurate renal function parameters had not been calculated.

Mohamadpour and colleagues reported no important difference in serum electrolytes parameters (such as calcium and phospho- 
rus), liver function tests and hormone levels (thyroxine, thyroidstimulating hormone, cortisol and testestron) between placebo and crocin-treated $(2 \mathrm{mg} / \mathrm{d})$ groups [32]. Serum concentrations of crocin and crocetin had not been reported by any of the mentioned studies.

Given that the majority of crocin is not absorbed via gastrointestinal tract, it might have given a better estimation of pharmacokinetic-pharmacodynamic relationship for crocin, if researchers had evaluated serum levels of crocin or crocetin.

In some of the clinical trials about the efficacy of saffron in the Alzheimer disease and depression, 15-30 mg/day of saffron capsule were prescribed and several minor adverse effects such as nausea, vomiting, dizziness, dry mouth and etc. have been reported. The commonest adverse effect of saffron was dry mouth (18 and 13\%) [36-39]. In a report by Modaghegh and colleagues in which they had treated their precipitance with higher doses, no minor adverse effects were mentioned. Such differences in these studies are probably related to the duration of treatment. Gout reported a few minor adverse effects such as nausea, diarrhea, and reflux in about $16 \%$ of volunteers; the overweight women receiving $174.5 \mathrm{mg} /$ day of saffron for 8 weeks. These side effects were no more than the placebo group [40]. On the other hand, it may be associated with recall bias in neurologic clinical trials in which researchers mentioned similar instances of adverse effects. The authors reported no significant difference between saffron and placebo regarding the side effects. Correlation between advancing age and rate of adverse drug reaction has been shown in some studies [41] and it may be another reason for such variation. For instance, the average age in Modaghegh's study (27.4-30 years) was lower than that in neurologic clinical trials (35-73years). Modaghegh et al. reported abnormal uterine bleeding in one female in each group of 200 and $400 \mathrm{mg}$ of saffron. As documented in traditional medicine, saffron had been used for abortion [39], and later in was shown to be able to induce uterine stimulants and have estrogenic effects in guinea pigs and mice, respectively [42]. This type of side effects were not described in Gout's study on 60 women with doses near to that of Modaghegh's study but with extended duration [40].

We could not find any study on the interactions between different drugs and saffron. However, in patients under anticoagulant therapy or those having certain types of renal insufficiency, a cautious approach for prescribing saffron is suggested.

\section{Cardiovascular}

$\checkmark$

The effects of crocin, an active constituent of $C$. sativus, have been studied in isoproterenol-induced cardiotoxicity in rats [43]. Either crocin $(5,10$ and $20 \mathrm{mg} / \mathrm{kg} /$ day $)$ or vehicle were administered orally for 21 days together with isoproterenol $(85 \mathrm{mg} / \mathrm{kg}$, subcutaneously, every $24 \mathrm{~h})$ on the last 2 days in order to induce cardiac dysfunction, which was indicated as low blood pressure. The results illustrated a possible cardioprotective effect for crocin in isoproterenol-induced cardiac toxicity via modulating oxidative stress resulted in maintaining the redox status of cells [44].

It has been shown that the aqueous extract of saffron stigma has hypotensive effect in rats, which is partly due to the actions of its 2 major constitutes, crocin and safranal; taking into account that safranal plays a greater role in decreasing the blood pressure in comparison to crocin [45].
In RDBPCCT used saffron tablets for one week on 30 healthy volunteers divided into 3 groups of placebo, 200 and $400 \mathrm{mg}$ saffron. The results demonstrated that saffron at dose of $400 \mathrm{mg}$ could significantly decrease standing systolic blood pressure and mean arterial pressures and increase serum sodium, BUN and $\mathrm{Cr}$. The biochemical changes were within the normal ranges and turned out to be clinically insignificant [28]. In addition, it has been shown that aqueous-ethanolic extract of saffron has a potent inhibitory effect on calcium channels of guinea pig isolated heart [46].

It has long been revealed that crocetin can almost completely prevent the induced atherosclerosis in rabbits, most likely through increasing the oxygenation of tissues [47]. In another study on rabbits, in which 2 out of 3 groups of animals received either high lipid diet alone or high lipid diet plus crocetin, crocetin was shown to have anti-atherosclerotic effect since it suppressed the expression of vascular cell adhesion molecule- 1 (VCAM-1), which might be due to deactivation of NF-kappa B [48]. However, there have been reports that the incidence of cardiovascular diseases is noticeably lower in the geographic parts where saffron is used in daily diet of inhabitants [49], taking into account that antioxidants and flavonoids, especially lycopene, that exist in saffron are proven to decrease the risk of cardiovascular diseases [50].

A clinical trial was held by Verma et al., showed the prospective effects of saffron on cardiovascular disorders. In this study, $50 \mathrm{mg}$ of saffron was dissolved in $100 \mathrm{ml}$ of milk and administered twice a day to 20 individuals, 10 of them suffering from heart disease. A constant decrease in lipoprotein oxidation susceptibility was investigated after 3 and 6 weeks; hence, the significant drop in LOS levels indicated a potential antioxidant effect for saffron [51].

Taking into account the anti-atherosclerotic, antioxidant, antidiabetes, hypotensive, anti-ischemic, anti-platelet aggregation and hypolipidemic effects of saffron, this herb can be considered as a promising treatment in decline of cardiovascular risk factors.

\section{Neuropsychology}

$\nabla$

\section{Alzheimer disease}

Alzheimer disease (AD) is the most frequent form of dementia [52]. It is estimated that 42 million people worldwide will suffer from AD by 2040 [53] and it will reach epidemic proportions. Diagnosis of $\mathrm{AD}$ is based on criteria and symptoms. The most common symptom pattern begins with a gradually worsening difficulty in remembering new information [53]. Few drugs have been developed to alleviate these cognitive symptoms, thus more practical and safe medications are required for the cognitive, behavioral and psychological symptoms of dementia [54]. Crocin and safranal are shown to inhibit the formation of soluble oligomers and following fibrillar assemblies in cell culture. It is assumed that they bind to hydrophobic patches provided in the intermediate structures and thereby inhibit protein aggregation. The simultaneous hydrophobic and hydrophilic properties of crocin result in a more effective action [54]. Due to antioxidant properties of $C$. sativus stigma constituents $[13,56]$, they are effective in Abeta fibrillogenesis and deposition in a concentration and time-dependent manner [57]. Abeta fibril formation and deposition is thought to be promoted by oxidation [57]. Diffuse and neurotic extracellular amyloid plaques and intracellu- 
lar neurofibrillary tangles in the hippocampus, cerebral cortex and other areas of the brain, that are essential for cognitive function, is considered to be associated with AD and other neurodegenerative disorders such as Parkinson disease $[53,55,58]$.

Chronic microglial activation produces various pro-inflammatory and neurotoxic factors that induce neuronal injury [7]; therefore, negative regulation of microglial activation is an alternative to treat neurodegenerative disorders. In cultured microglial cells of rat brain, crocin and crocetin could inhibit LPS-induced nitric oxide (NO) release and result in reducing tumor necrosis factor-alpha, interleukin-1beta, and intracellular reactive oxygen species, as well as showing neuroprotection effect and inhibiting the hippocampal cells death [7].

Shams and colleagues reported that aqueous extract of saffron can improve learning and memory. Their results also indicated that aqueous extract of saffron increases brain dopamine and glutamate concentrations, whereas it could change neither brain serotonin nor norepinephrine [58]. The effectiveness of saffron extract and crocin on memory enhancing in chronic cerebral hypoperfusion in rat has been reported [16]. It was reported that administration of $C$. sativus extracts could antagonize ethanol, acetaldehyde and scopolamine-induced memory impairment in rat and mouse $[10,13,59]$

There are 2 clinical trials on patients with mild-to-moderate AD $[36,37]$, the first one being a 16-week, RDBPCCT [36] and the second being a 22-week, multicenter, RDBPCCT [37]. On both studies, diagnosis of AD was based on the criteria of Diagnostic and Statistical Manual of Mental Disorders. Efficacy of treatment was evaluated by changing in AD Assessment Scale and cognitive subscale and Clinical Dementia Rating Scale. Akhondzadeh et al. treated patients with dose of $30 \mathrm{mg} /$ day (15 mg twice a day) of saffron or placebo for 16 weeks in first, and also with either $30 \mathrm{mg} /$ day saffron capsules (15 mg twice a day) or donepezil $10 \mathrm{mg} /$ day ( $5 \mathrm{mg}$ twice a day) for 22 weeks in the second study $[36,37]$. Authors reported that saffron produced a significantly superior outcome on cognitive function than the placebo. They also showed that the effectiveness of saffron on improving the cognition score of AD patients was equal to that of donepezil, both decreasing the score in Alzheimer's Disease Assessment Scale by about 3.7, and the score of Clinical Dementia Rating Scale by $0.7-0.8$. Although saffron was shown to possess adverse effects, they were no more than the placebo or donepezil.

Both studies were designed very well as multicenter doubleblind clinical trials, although they did not completely define the etiology in their patients $[36,37]$. Prescribing saffron for AD patients requires more extended studies with bigger sample size and different types of etiologies.

\section{Depression}

Depression is the fourth cause of disability worldwide [60]. In Persian traditional medicine, saffron is used for depression [62]. Hosseinzadeh et al. reported the antidepressant effect of $C$. sativus stigma extracts as well as safranal and crocin in mice being assessed by forced swimming test. Safranal $(0.15-0.5 \mathrm{ml} / \mathrm{kg})$ and crocin $(50-600 \mathrm{mg} / \mathrm{kg}$ ) could reduce the immobility time, and both extracts increased swimming time similar to fluoxetine and increased climbing time like to imipramine [61]. It seems that crocin may inhibit uptake of dopamine and norepinephrine, and safranal acts via serotonin [6,61]. There are some other papers about effectiveness of saffron against depression on different animal models $[5,63,64]$. Saffron has also been reported to have anxiolytic effects in animal models [65].
C. sativus extract has been used in some antidepressant clinical trials ( Table 1). The antidepressant effects of saffron were compared with placebo in 2 studies $[38,39]$, with fluoxetine in 2 studies [62,66], and with imipramine in one study [60]. Another study compared outcome of patients who received combination of fluoxetine with saffron or placebo [18].

Researchers have attempted to perform clinical trials on most typical antidepressants with the inclusion criteria, such as age ranges (18-65 years old) and frequency of genders, and exclusion criteria, e.g. co-morbidity of psychiatric illness, specific types of personality disorders etc. [67]. Participants were outpatients who met the DSM- IV criteria for major depression (mild to moderate depression).

Sample size were equal $(\mathrm{n}=30-40)$ in all studies, although some of the reviewers stated that their sample sizes were not enough [68]. All of these studies were performed on similar population. Because of the effect of various social factors on depression, a multicenter clinical trial seemed to be more of use.

Antidepressant effect of saffron was evaluated by the Hamilton Depression Rating Scale (HAM-D). It is shown that saffron could decrease HAM-D about $10-14 \%$, generally considered as remission ( $\bullet$ Table 1) [67].

Based on clinical trial guidelines, a minimum of 4-6 weeks appear to be an appropriate duration [67] which has been observed by all of them; although, this could not reflect the preventive effect of saffron on exacerbation of depression and needs to be evaluated in extended studies.

In 2 studies $[38,39]$ which compared saffron with placebo, authors reported no significant differences between the 2 groups in terms of observed side effects. Nevertheless, it seems that the total number of reported adverse effect by patients in saffron group were more than that of control (29 vs. 13 and 17 vs. 10). The most frequent adverse effect of saffron which had been reported in all trial was anxiety ( $\bullet$ Table 2 ) followed by an increase or a decrease in the appetites, nausea and headache. None of these studies had any report about past medical history of their participants. This is not entirely obvious whether they were treated with other medications before being included in the study. Furthermore, the authors did not completely defined whether patients were treated with other psychological treatments, such as psychotherapy or family therapy.

Through our review of the literatures, we found another clinical trial on the effect of saffron on premenstrual syndrome [69]. The researchers had used 17-item HAM-D scoring for evaluating the outcome. They showed that administration of $30 \mathrm{mg} /$ day $(15 \mathrm{mg}$ twice a day) saffron capsules for 2 menstrual cycles could reduce the depression score as well as the menstruation symptoms ( $\bullet$ Table 1 ) in comparison to placebo. The most reported adverse effect of saffron on this study was a change in appetite ( $\bullet$ Table 2).

We also found 2 other abstracts of clinical trial on antidepressant effect of saffron that were presented in congresses as poster presentation. They had evaluated the antidepressant effect of saffron by BECK depression score [70,71]. One abstract had studied effect of drinking a saffron- containing tea for 4 weeks in medical students. It was revealed that saffron could reduce depression score [70]. The aim of the other study was to evaluate the effect of $100 \mathrm{mg} /$ day saffron vs. placebo in 70 patients for 12 weeks [71], also reporting the effectiveness of saffron. However, these 2 studies had a bigger sample sizes $(n=50$ and 70) and a longer treatment duration ( 4 and 12 weeks) than the previous 
Table 1 Characteristics of clinical trials of antidepressant effect of saffron and their results.

\begin{tabular}{|c|c|c|c|c|c|c|c|c|}
\hline Type of study & population & $\begin{array}{l}\text { Sample } \\
\text { size }\end{array}$ & scale & $\begin{array}{l}\text { Type of ad- } \\
\text { ministration } \\
\text { compounds }\end{array}$ & $\begin{array}{l}\text { Compared } \\
\text { with }\end{array}$ & Duration & Results & $\begin{array}{l}\text { Author (Year) } \\
\text { (reference) }\end{array}$ \\
\hline Pilot DBRCT & $\begin{array}{l}\text { Adult outpatients } \\
\text { with mild to moder- } \\
\text { ate depression }\end{array}$ & 40 & 17-item HAM-D. & $\begin{array}{l}\text { petal of } C \text {. } \\
\text { sativus } 15 \mathrm{mg} \\
\text { bid }\end{array}$ & $\begin{array}{l}\text { Fluoxetine } \\
10 \mathrm{mg} \text { bid }\end{array}$ & 8 weeks & $\begin{array}{l}\text { effective similar to } \\
\text { fluoxetine } \\
(\mathrm{F}=0.03 \text {, d.f. }=1 \text {, } \\
P=0.84)\end{array}$ & $\begin{array}{l}\text { Akhondzadeh } \\
\text { (2007) [66] }\end{array}$ \\
\hline $\begin{array}{l}\text { placebo-con- } \\
\text { trolled DBRCT }\end{array}$ & $\begin{array}{l}\text { adult outpatients } \\
\text { with mild to moder- } \\
\text { ate depression }\end{array}$ & 40 & 17-item HAM-D. & $\begin{array}{l}\text { capsule of } \\
\text { petal of } C \text {. } \\
\text { sativus } 30 \mathrm{mg} / \\
\text { day (BD) }\end{array}$ & placebo & 6 weeks & $\begin{array}{l}\text { a significantly better } \\
\text { outcome than placebo } \\
\text { (d.f. }=1, F=16.87 \text {, } \\
p<0.001 \text { ) }\end{array}$ & $\begin{array}{l}\text { Moshiri (2006) } \\
\text { [39] }\end{array}$ \\
\hline $\begin{array}{l}\text { single-centre } \\
\text { placebo-con- } \\
\text { trolled DBRCT }\end{array}$ & $\begin{array}{l}\text { adult outpatients } \\
\text { with mild to moder- } \\
\text { ate depression }\end{array}$ & 40 & 17-item HAM-D. & $\begin{array}{l}\text { capsule } \\
\text { of saffron } \\
30 \mathrm{mg}[\text { sol]day } \\
\text { (BD) }\end{array}$ & placebo & 6 weeks & $\begin{array}{l}\text { a significantly better } \\
\text { outcome than placebo } \\
\text { (d.f. }=1, F=18.89 \text {, } \\
p<0.001 \text { ) }\end{array}$ & $\begin{array}{l}\text { Akhondzadeh, } \\
\text { (2005) [38] }\end{array}$ \\
\hline DBRCT & $\begin{array}{l}\text { adult outpatients } \\
\text { with mild to moder- } \\
\text { ate depression }\end{array}$ & 40 & 17-item HAM-D. & $\begin{array}{l}\text { (hydro-alco- } \\
\text { holic extract) } \\
\text { saffron } 30 \mathrm{mg} / \\
\text { day (BD) }\end{array}$ & $\begin{array}{l}\text { Fluoxetine } \\
20 \mathrm{mg} / \text { day } \\
\text { (BD) }\end{array}$ & 6 weeks & $\begin{array}{l}\text { effective similar to } \\
\text { fluoxetine } \\
(\mathrm{F}=0.13 \text {, d.f. }=1 \text {, } \\
\mathrm{P}=0.71)\end{array}$ & $\begin{array}{l}\text { Noorbala } \\
\text { (2005) [62] }\end{array}$ \\
\hline $\begin{array}{l}\text { single-center } \\
\text { DBRCT }\end{array}$ & $\begin{array}{l}\text { adult outpatients } \\
\text { with mild to moder- } \\
\text { ate depression }\end{array}$ & 30 & 17-item HAM-D. & $\begin{array}{l}\text { capsule of } \\
\text { saffron } 30 \mathrm{mg} / \\
\text { day (TDS) }\end{array}$ & $\begin{array}{l}\text { capsule of } \\
\text { imipramine } \\
100 \mathrm{mg} / \\
\text { day (TDS) }\end{array}$ & 6 weeks & $\begin{array}{l}\text { to be effective similar } \\
\text { to imipramine } \\
(\mathrm{F}=2.91 \text {, d.f. }=1 \text {, } \\
\mathrm{P}=0.09)\end{array}$ & $\begin{array}{l}\text { Akhondzadeh, } \\
\text { (2004) [60] }\end{array}$ \\
\hline $\begin{array}{l}\text { placebo-con- } \\
\text { trolled DBRCT }\end{array}$ & $\begin{array}{l}\text { women (20-45 } \\
\text { y) with regular } \\
\text { menstrual cycles } \\
\text { and PMS at least } 6 \\
\text { months }\end{array}$ & 50 & $\begin{array}{l}\text { 17-item HAM-D. } \\
\& \text { checklist of } 17 \\
\text { premenstrual } \\
\text { daily symptoms }\end{array}$ & $\begin{array}{l}\text { capsule saffron } \\
30 \mathrm{mg} / \text { day } \\
\text { (15 mg twice } \\
\text { a day }\end{array}$ & placebo & $\begin{array}{l}\text { For a } 2 \\
\text { menstrual } \\
\text { cycles }\end{array}$ & $\begin{array}{l}\text { effective in relieving } \\
\text { symptoms of PMS }\end{array}$ & $\begin{array}{l}\text { Agha-Hosseini } \\
\text { (2008) [69] }\end{array}$ \\
\hline $\begin{array}{l}\text { double- } \\
\text { blinded }\end{array}$ & medical students & 50 & BDI scale & $\begin{array}{l}\text { drank tea } \\
\text { contained- } \\
\text { saffron in } 3 \\
\text { times in day }\end{array}$ & $\begin{array}{l}\text { Pre-test } \\
\text { Post-test }\end{array}$ & 4 weeks & $\begin{array}{l}\text { decreasing of The } \\
\text { mean score } \\
(P<0.0001)\end{array}$ & $\begin{array}{l}\text { Masinaei } \\
\text { Nezhad, } \\
(2005)[70]\end{array}$ \\
\hline DBRCT & $\begin{array}{l}\text { adult patients who } \\
\text { completed a ques- } \\
\text { tionnaire (BDI) }\end{array}$ & 70 & BDI scale & $\begin{array}{l}\text { capsule of saf- } \\
\text { fron } 100 \mathrm{mg} / \\
\text { day }\end{array}$ & placebo & 12 weeks & $\begin{array}{l}\text { the BDI score in saf- } \\
\text { fron group decreased } \\
\text { about } 2 \text { times than } \\
\text { that of placebo group }\end{array}$ & $\begin{array}{l}\text { Shemshian, } \\
\text { (2011) [71] }\end{array}$ \\
\hline
\end{tabular}

DBRCT = double-blind, randomized clinical trial, HAM-D = Hamilton Depression Rating Scale, BDI = Beck Depression Inventor

Table 2 The frequency of saffron's adverse effects through clinical trials on depression. Number (percent). Total number of cases are 129 patients.

\begin{tabular}{|c|c|c|c|c|c|c|c|c|}
\hline $\begin{array}{l}\text { Author [year] } \\
\text { (reference) }\end{array}$ & $\begin{array}{l}\text { Mansoori P } \\
\text { [2011] [20] }\end{array}$ & $\begin{array}{l}\text { Akhondzadeh } \\
\text { Basti [2007] [66] }\end{array}$ & $\begin{array}{l}\text { Akhondzadeh } \\
\text { S [2004] [60] }\end{array}$ & $\begin{array}{l}\text { Akhondzadeh } \\
\text { S [2005] [38] }\end{array}$ & $\begin{array}{l}\text { Moshir E } \\
\text { [2006] [39] }\end{array}$ & $\begin{array}{l}\text { Noorbala A } \\
\text { [2005] [62] }\end{array}$ & $\begin{array}{l}\text { Agha-Hosseini } \\
{[2008][69]}\end{array}$ & Total \\
\hline Compare with & placebo & fluoxetine & imipramine & placebo & placebo & fluoxetine & placebo & \\
\hline Anxiety & $2(20)$ & $4(20)$ & $4(26.7)$ & $3(15)$ & $4(20)$ & $3(15)$ & & $20(16)$ \\
\hline Decreased appetite & & $5(25)$ & $2(13.3)$ & $2(10)$ & $4(20)$ & $2(10)$ & $3(12.5)$ & $18(14)$ \\
\hline Increased appetite & & $1(5)$ & $1(6.7)$ & $5(25)$ & & $5(25)$ & $4(16.7)$ & $16(12)$ \\
\hline Nausea & & $3(15)$ & $2(13.3)$ & $2(10)$ & $5(25)$ & $2(10)$ & $2(8.3)$ & $16(12)$ \\
\hline Headache & & $2(10)$ & $3(20)$ & $3(15)$ & $3(15)$ & $3(15)$ & $3(12.5)$ & $17(13)$ \\
\hline Heart pounding & & $3(15)$ & & & $4(20)$ & & & $7(5)$ \\
\hline Hypomania & & & $2(13.3)$ & $2(10)$ & & & $2(8.3)$ & $6(5)$ \\
\hline Tremor & & $2(10)$ & & & $3(15)$ & & & $5(5)$ \\
\hline Dry mouth & $3(30)$ & & $1(6.6)$ & & & & & $4(3)$ \\
\hline Sweating & & $2(10)$ & & & $2(10)$ & & & $4(3)$ \\
\hline Stomach pain & & & & & $4(20)$ & & & $4(3)$ \\
\hline Constipation & $1(10)$ & & $2(13.3)$ & & & & & $3(2)$ \\
\hline Sexual dysfunction & & $3(15)$ & & & & & & $3(2)$ \\
\hline Restlessness & $2(20)$ & & & & & & & $2(2)$ \\
\hline Insomnia & & $2(10)$ & & & & & & $2(2)$ \\
\hline Daily drowsiness & $1(10)$ & & & & & & & $1(1)$ \\
\hline Morning drowsiness & $1(10)$ & & & & & & & $1(1)$ \\
\hline Sedation & & & & $1(5)$ & & $1(5)$ & $1(4.2)$ & $3(2)$ \\
\hline Urinary retention & & & $1(6.7)$ & & & & & $1(1)$ \\
\hline Total & 10 & 27 & 20 & 18 & 29 & 16 & 15 & 133 \\
\hline
\end{tabular}


studies. Since the abstracts were only published, we could not assess the studies thoroughly.

It seems that now is the time for evaluating antidepressant effect of saffron by multicenter, crossover, and large scale as third phase of clinical trials.

\section{Physical fatigue}

Production of reactive oxygen species and free radicals, which are responsible for exercise-induced protein oxidation and contributes to physical fatigue, is promoted during muscular exercise $[72,73]$. Administration of crocetin as an antioxidant $[56,74]$ may attenuate physical fatigue. Mizuma and colleagues evaluated efficacy of $15 \mathrm{mg}$ of crocetin in a double-blind, placebocontrolled, 3-way crossover study on physical fatigue in 14 Japanese healthy volunteers ( 7 men and 7 women) for 8 days [75]. They administrated crocetin ( $15 \mathrm{mg} /$ day), ascorbic acid (3000 mg), or placebo capsules for 1 week before the experimental procedure. They found that men, who received crocetin alone, had significantly higher change in maximum velocity from 30- to 210-min. They could not find such difference in women [75]. The authors related their finding to antioxidant and alveolar oxygen transport augmentation properties of crocetin. However, they had not measured and reported any oxidant or antioxidant biomarkers or criteria of oxygenation.

\section{Endocrinology and Gynecology}

\section{Erection dysfunction (ED) and infertility}

Recently, different herbal remedies have been assessed as effective treatments for male infertility and other male sexual dysfunctions. Saffron has been known for centuries to have aphrodisiac properties. Moreover, the aphrodisiac activities of saffron aqueous extract and its constituent crocin, in male rats have been previously declared [76].

In a pilot clinical study on 20 men with erectile dysfunction, patients were observed for 10 days taking $200 \mathrm{mg}$ tablets of saffron every morning. The results showed a statistically significant improvement in both tip and base rigidity and tumescence. Moreover, saffron was considered positively effective on sexual function of patients with erectile dysfunction even after a shorttime treatment [77]. However, this was a pilot study and the sample number was rather few. Additionally, there were no control group and no placebo was utilized.

In a similar study to assess the efficacy and safety of saffron in erectile dysfunction, after 4 weeks of baseline evaluation, 346 men with erectile dysfunction received Sildenafil or saffron (30 mg BID) for 12 weeks. No significant improvements were observed in the international index of erectile function domains, Sexual Encounter Profile questions and Erectile Dysfunction Inventory of Treatment Satisfaction questionnaire scores with saffron administration. The authors reported that their findings did not support beneficial effects of saffron administration in men with erectile dysfunction [78]. This might be attributed to the low dose of saffron ( $30 \mathrm{mg}$ BID) prescribed in comparison to the previous study.

On the other hand, Safarinejad et. al studied the effect of saffron vs. placebo on idiopathic male factor infertility on 260 infertile men with idiopathic oligo-asthenoteratozoospermia (OAT). Patients received either $60 \mathrm{mg} /$ day saffron or placebo for 26 weeks. Afterwards, the 2 groups were compared with each other regarding changes in semen parameters and total seminal plasma antioxidant capacity. The results of the study showed saffron did not improve semen parameters in infertile men with idiopathic OAT [79].

In a case-report a 25-year-old woman with a 2-year primary infertility who was diagnosed with unilateral tubal blockage, received Unani herbal Majoon, one of its ingredients being $C$. sativus, for 2 successive cycles. The outcome was the patient's pregnancy 2 months after therapy. C. sativus L. was reported to recover infertility due to crocetin and flavonoids contents. [80]. Nevertheless, it cannot be directly concluded whether or not the positive result was due to saffron.

\section{Premenstrual syndrome (PMS)}

The effect of saffron has been studied on some gynecologic disorders, mostly on premenstrual syndrome (PMS). PMS is a group of cyclical and recurrent emotional, physical, psychological, and mood discomfort that typically occurs after ovulation and before the onset of menstrual period [81].

A RDBPCCT study investigated the effect of stigma of saffron on relieving the symptoms of this syndrome on 20-45 aged women with; regular menstrual cycles and the experience of the symptoms of PMS for at least 6 months.They received either $30 \mathrm{mg}$ per day saffron or placebo. PMS symptoms were evaluated using a Premenstrual Daily Symptoms (PDS) questionnaire and Hamilton Depression Rating Scale (HAM-D). There was a significant difference in the efficacy of saffron in the Total PDS and HAM-D. The results indicated the positive effect of C. sativus L. in alleviation of PMS symptoms [69].

\section{Primary dysmenorrhea}

Primary dysmenorrhea, with a prevalence rate of approximately $90 \%$, is described as cramping pains in the lower abdomen before or throughout the menstruation period without the presence of other diseases [82]. The effect of saffron has been assessed in the treatment of primary dysmenorrhea using a pilot RDBPCCT on 180 female students aged 18-27 years old suffering from primary dysmenorrhea. Individuals were randomly divided into 3 groups taking either herbal drugs (saffron, celery seed, and anise extracts 3 times a day for 3 days) or mefenamic acid or placebo, starting from the onset of bleeding or pain. Severity and duration of pain were evaluated for 3 months. Both herbal and chemical drugs efficiently comforted the menstrual pain in comparison with the placebo [83]. However, since the herbal drug contained 3 herbs, this effect cannot be attributed to a specific herb.

Another study attempted to elucidate the effects of saffron odor on some gynecologic symptoms including PMS, dysmenorrhea and irregular menstruation. 35 women with normal olfactory ability and normal menstrual cycles were exposed to saffron odor for $20 \mathrm{~min}$. Saliva samples were subsequently analyzed for cortisol, testosterone and 17-beta estradiol concentrations utilizing enzyme immunoassay method. The State-Trait Anxiety Inventory (STAI) was used for psychological testing. The outcome was a considerable decline in cortisol levels and an increase in estradiol levels after exposure to saffron odor in both follicular and luteal phases. Moreover, the STAI score decreased in the follicular and luteal phases in the saffron group. Therefore, the findings of this RDBPCCT suggested positive physiological and psychological effects of saffron odor in management of PMS, dysmenorrhea and irregular menstruation [84]. However, in this study the fragrance of saffron was diluted in ethanol to be 
smelled by the test individuals, a fact that implies that such solvent may be considered an effective treatment.

\section{Snacking and appetites}

Snacking and compulsive eating are disturbed dietary behaviors which are consequence of mood disorders. Stress-induced eating accompanied with a preference for high-sugar and high-fat food consumption, is powerful reinforcing of snacking [85]. Several studies have shown mood elevation and anti-anxiety properties of saffron $[39,61,65,66]$. Gout et al. evaluated the effect of saffron on reducing the snacking frequency and demand, in 60 healthy, mildly overweight women, during a RDBPCCT [40]. They administrated $176.5 \mathrm{mg}$ extract of saffron or placebo per day over an 8-week period and recorded body weight changes and snacking frequency. They found that saffron caused a significantly greater body weight reduction than the placebo after 8 weeks, and a significant decrease in snacking frequency after 4 weeks. However, other anthropometric dimensions and vital signs did not not change between the saffron and placebo groups [40]. They reported no major adverse effects as well. Therefore, they have offered saffron as an adjuvant supplement for people involved in weight loss programs whose weight gain is particularly due to stress or depression [40].

\section{Immunology and Allergy}

Feo et al. have studied the sensitization to saffron and its clinical significance as an occupational allergen [86]. In their study, 2 groups of subjects were included: one group was exposed to saffron in an important saffron area of Spain as workers (picking, manual extraction of stigmas, and roasting the stigmas of saffron), and the other group comprised of 237 unexposed patients with a positive history of allergy. Individuals having positive Skin Prick test afterward went through Radioallergosorbent test (RAST) to evaluate the cutaneous and specific antibody responses. Saffron allergens from pollen and stamens were then characterized by SDS-PAGE immunoblotting. No allergens were verified in pistils [86].

In another study directed in Iran, more than 200 saffron workers referring to an allergy clinic were evaluated regarding the clinical symptoms and Prick test. Results illustrated that saffron, and in particular its pollen, was an inhalation allergen and female workers were more sensitive to this plant than the male ones [87].

The effects of $100 \mathrm{mg}$ saffron tablets taken daily for 6 weeks, were evaluated on 45 healthy middle-aged men through a RDBPCCT [88]. Different hematological and immunological parameters were assessed 3 weeks after treatment. Saffron increased IgG levels while decreasing IgM levels in comparison with the baseline and the placebo. Moreover, it could decrease the percentage of basophils and also the platelets count, but it increased the percentage of monocytes. The results of this study suggested that a sub-chronic daily dose of $100 \mathrm{mg}$ saffron had short-term immunomodulatory effects with no side effects [88].

\section{Skin}

As one of the Persian traditional medications, saffron, has been used in order to add shine, lighten the skin and reduce dark pigments, dark circles under the eyes, acne and pimple [89]. It is suspected that crocin inhibits active compound of DNA damage, or acts as an activator for DNA excision repair enzymes [90]. Furthermore, saffron has antisolar effect and can absorb UV rays of sun [91].

Vyas et al. used $3 \%$ dry extract of saffron being inoculated in o/w cream, lotion and face powder formulations and tested it by patch test on individuals in age groups of 18-28. They reported that saffron could clearly enlighten the skin. They suggested these effects are due to crocin and crocetin presented in saffron [92]. The shining and depigmentation effects of saffron may be attributable to antioxidant effect of crocin and crocetin $[17,93]$. However, Vyas had no appropriate methodological clinical trial criteria such as number of groups, control group and the human method. We could not find any other article about the effect of saffron on skin.

Saffron has been used as an ingredient in anti-itching creams possessing emollient and antipruritic effects in a unicentric, open label randomized controlled study [94]. For the case group, a topical polyherbal formulation cream containing extracts of turmeric 16\% (Curcuma longa), saffron $0.025 \%$ (C. sativus), sandalwood $8 \%$ (Santalum album), vetiver $0.5 \%$ (Veteveria zizanioides), lata kasturi 0.1\% (Abelmoschus moschatus), mehendi 3\% (Lawsonia inermis), tulasi 3\% (Ocimum sanctum), yastimadhu $0.5 \%$ (Glycyrrhiza glabra), turmeric oil $0.1 \%$, surasar $0.5 \%$, and swarna bhasma $0.00032 \%$ in a nongreasy cream base was used. They applied standard antipuritic cream containing urea, lactic acid, propylene glycol and light liquid paraffin. They reported that this application could reduce both pruritus and composite scores in case group as well as in the control standard group. Adverse events like mild local skin irritation and burning sensation at the site of application were reported in only 3 out of 25 cases, being as frequent as in the control group [94]. However, this is the only clinical trial on antipuritic effect of saffron and the results are not utterly related to saffron.

\section{Conclusion \\ $\nabla$}

Saffron and its constituents are shown to possess multiple useful effects on several diseases such as Alzheimer and depression as well as in gynecology disorders. Due to high safety level of this phytomedicine, it can be applied in clinical trials for majority of its effects. Some applications of saffron such as antidepressant and anti-Alzheimer properties are sufficient for the subsequent phase of clinical trials or drug developments. However, most of others effects and applications of saffron require further clinical and animal studies.

\section{Acknowledgment \\ $\nabla$}

The authors thank Miss Golbarg Khorsand (Doctor of Philosophy (PhD), English Literature Shiraz University, Iran) for English copy-editing the manuscript. Institution where the study was performed is School of Pharmacy, Mashhad University of Medical Sciences, Mashhad, IR. Iran.

\section{Conflict of Interest}

\section{$\nabla$}

The authors have no conflicts of interest to declare. 


\section{References}

1 Kianbakht S. A systematic review on pharmacology of saffron and its active constituents. J Med Plants 2009; 28: 1-23 (in persion)

2 Koocheki A, Ganjeali A, Abbassil F. The effect of duration and condition of incubation, weight of mother corms and photoperiod on corm and shoot characteristics of saffron plant (Crocus sativus L.). J Iran Field Crop Res 2006; 4: 20-25 (in persion)

3 Hosseinzadeh $H$, Talebzadeh F. Anticonvulsant evaluation of safranal and crocin from Crocus sativus in mice. Fitoterapia 2005; 76: 722-724

4 Hosseinzadeh H, Sadeghnia HR. Protective effect of safranal on pentylenetetrazol-induced seizures in the rat: involvement of GABAergic and opioids systems. Phytomedicine 2007; 14: 256-262

5 Wang Y, Han T, Zhu Y et al. Antidepressant properties of bioactive fractions from the extract of Crocus sativus L. J Nat Med 2010; 64: 24-30

6 Hosseinzadeh H, Karimi G, Niapoor M. Antidepressant effects of Crocus sativus stigma extracts and its constituents, crocin and safranal, in mice. J Med Plants 2004; 3: 48-58

7 Nam KN, Park YM, Jung HJ et al. Anti-inflammatory effects of crocin and crocetin in rat brain microglial cells. Eur J Pharmacol 2010; 648: $110-116$

8 Hosseinzadeh H, Younesi HM. Antinociceptive and anti-inflammatory effects of Crocus sativus L. stigma and petal extracts in mice. BMC Pharmacol 2002; 2: 7

9 Nair SC, Pannikar B, Panikkar KR. Antitumour activity of saffron (Crocus sativus). Cancer Lett 1991; 57: 109-114

10 Zhang Y, Shoyama Y, Sugiura $M$ et al. Effects of Crocus sativus L. on the ethanol-induced impairment of passive avoidance performances in mice. Biol Pharm Bull 1994; 17: 217-221

11 Abe K, Saito $H$. Effects of saffron extract and its constituent crocin on learning behaviour and long-term potentiation. Phytother Res 2000; 14: $149-152$

12 Hosseinzadeh H, Sadeghnia HR, Ghaeni FA et al. Effects of saffron (Crocus sativus 1. ) and its active constituent, crocin, on recognition and spatial memory after chronic cerebral hypoperfusion in rats. Phytother Res 2012; 26: 381-386

13 Hosseinzadeh H, Ziaei T. Effects of Crocus sativus stigma extract and its constituents, crosin and safranal, on intact memory and scopolamine -indused learning deficits in rats performing the Morris water maze task. J Med Plants 2006; 5: 40-50

14 Abdullaev Jafarova F, Caballero-Ortega H, Riveron-Negrete L et al. In vitro evaluation of the chemopreventive potential of saffron. Rev Invest Clin 2002; 54: 430-436

15 Premkumar K, Abraham SK, Santhiya ST et al. Protective effects of saffron (Crocus sativus Linn.) on genotoxins-induced oxidative stress in Swiss albino mice. Phytother Res 2003; 17: 614-617

16 Mohajeri SA, Hosseinzadeh H, Abbasi-Ghaeni F. Saffron (Crocus sativus L.) and crocin have memory enhancing effect after chronic cerebral hypoperfusion in rats. J Clinbiochem 2011; 8: 274

17 Hosseinzadeh H, Sadeghnia HR, Ziaee T et al. Protective effect of aqueous saffron extract (Crocus sativus L.) and crocin, its active constituent, on renal ischemia-reperfusion-induced oxidative damage in rats. J Pharm Pharm Sci 2005; 8: 387-393

18 Mansoori P, Akhondzadeh S, Raisi F et al. A Randomized, Doubleblind, Placebo - controlled Study of Safety of the Adjunctive Saffron on Sexual Dysfunction Induced by a Selective. J Med Plants 2011; 10: $121-130$

19 Ramadan A, Soliman G, Mahmoud SS et al. Evaluation of the safety and antioxidant activitie $s$ of Crocus sativus and Propolis ethanolic extracts. J Saudi Chem Soci 2012; 16: 13-21

20 Mansoori P, Akhondzadeh S, Raisi F et al. A randomized, double-blind, placebo-controled, study of safety the adjunctive saffron on sexual dysfunction induced by selective sertonin reuptake inhibitor. J Med Plants 2011; 10: 121-130

21 Mohajeri D, Mousavi G, Mesgari M et al. Subacute toxicity of Crocus sativus 1. (saffron) stigma ethanolic extract in rats. Am J Pharma Toxi 2007; 2: 189-193

22 Asai A, Nakano T, Takahashi $M$ et al. Orally administered crocetin and crocins are absorbed into blood plasma as crocetin and its glucuronide conjugates in mice. J Agric Food Chem 2005; 53: 7302-7306

23 Xi L, Qian Z, Du P et al. Pharmacokinetic properties of crocin (crocetin digentiobiose ester) following oral administration in rats. Phytomedicine 2007; 14: 633-636

24 Singla CK, Bhat GV. Crocin: An Overview. Indo Glo J Pharmaceu Sci 2011; 1: 281-286

25 Liu TZ, Qian ZY. Pharmacokinetics of crocetin in rats. Yao Xue Xue Bao 2002; 37: 367-369
26 Tang L, Yan F, Xu Y et al. Determination of crocin-1 in rabbit plasma and the pharmacokinetics by RP-HPLC. Yao Xue Xue Bao 2004; 39: 854-856

27 Umigai $N$, Murakami K, Ulit MV et al. The pharmacokinetic profile of crocetin in healthy adult human volunteers after a single oral administration. Phytomedicine 2011; 18: 575-578

28 Modaghegh MH, Shahabian M, Esmaeili HA et al. Safety evaluation of saffron (Crocus sativus) tablets in healthy volunteers. Phytomedicine 2008; 15: 1032-1037

29 Drugs.com:. Saffron http://www.drugs.com/npp/saffron.html 2012

$30 \mathrm{Rx}$-list (The internt drug index). saffron, http://www.rxlist.com/ saffron-page2/supplements.htm (Accessed 14/5/2012) http://www. rxlist.com/saffron-page2/supplements.htm

31 Schmidt M, Betti G, Hensel A. Saffron in phytotherapy: pharmacology and clinical uses. Wien Med Wochenschr 2007; 157: 315-319

32 Mohamadpour AH, Ayati Z, Parizadeh MR et al. Safety Evaluation of Crocin (a constituent of saffron) Tablets in Healthy Volunteers. Iran J Basic Med Sci 2013; 15: 24-31

33 Okano K, Nishio T, Fukaya C et al. Isolation and identification of a platelet aggregation inhibitor from saffron (Crocus sativus Linne, Iridaceae). Wakan Iyaku Gakka ish 1992; 9: 175-181

34 He SY, Qian ZY, Tang FT et al. Effect of crocin on experimental atherosclerosis in quails and its mechanisms. Life Sci 2005; 77: 907-921

$35 \mathrm{Xu}$ GL, Yu SQ Gong ZN et al. Study of the effect of crocin on rat experimental hyperlipemia and the underlying mechanisms. Zhongguo Zhong Yao Za Zhi 2005; 30: 369-372

36 Akhondzadeh S, Sabet MS, Harirchian MH et al. Saffron in the treatment of patients with mild to moderate Alzheimer's disease: a 16-week, randomized and placebo-controlled trial. J Clin Pharm Ther 2010; 35: $581-588$

37 Akhondzadeh S, Shafiee Sabet M, Harirchian MH et al. A 22-week, multicenter, randomized, double-blind controlled trial of Crocus sativus in the treatment of mild-to-moderate Alzheimer's disease. Psychopharmacol (Berl) 2010; 207: 637-643

38 Akhondzadeh S, Tahmacebi-Pour N, Noorbala AA et al. Crocus sativus L. in the treatment of mild to moderate depression: a double-blind, randomized and placebo-controlled trial. Phytother Res 2005; 19: 148-151

39 Moshiri E, Basti AA, Noorbala AA et al. Crocus sativus L. (petal) in the treatment of mild-to-moderate depression: a double-blind, randomized and placebo-controlled trial. Phytomedicine 2006; 13: 607-611

40 Gout B, Bourges C, Paineau-Dubreuil S. Satiereal, a Crocus sativus L extract, reduces snacking and increases satiety in a randomized placebo-controlled study of mildly overweight, healthy women. Nutr Res 2010; 30: 305-313

41 Routledge PA, O'Mahony MS, Woodhouse KW. Adverse drug reactions in elderly patients. Br J Clin Pharmacol 2004; 57: 121-126

42 Chang PY, Wang CK, Liang JD et al. Studies on the pharmacological action of zang hong hua (Crocus sativus 1.). i. effects on uterus and estrus cycle. Yao Xue Xue Bao 1964; 11: 94-100

43 Mehdizadeh R, Parizadeh MR, Khooei AR et al. Cardioprotective effect of saffron extract and safranal in isoproterenol-induced myocardial infarction in Wistar rats. Iran J Basic Med Sci 2013; 16: 56-63

44 Goyal SN, Arora S, Sharma AK et al. Preventive effect of crocin of Crocus sativus on hemodynamic, biochemical, histopathological and ultrastuctural alterations in isoproterenol-induced cardiotoxicity in rats. Phytomedicine 2011; 17: 227-232

45 Imenshahidi $M$, Hosseinzadeh $H$, Javadpour $Y$. Hypotensive effect of aqueous saffron extract (Crocus sativus L.) and its constituents, safranal and crocin, in normotensive and hypertensive rats. Phytother Res 2010; 24: 990-994

46 Boskabady MH, Shafei MN, Shakiba A et al. Effect of aqueous-ethanol extract from Crocus sativus (saffron) on guinea-pig isolated heart. Phytother Res 2008; 22: 330-334

47 Gainer JL, Chisolm GM 3rd. Oxygen diffusion and atherosclerosis. Atheroscl 1974; 19: 135-138

48 Zheng S, Qian Z, Tang F et al. Suppression of vascular cell adhesion molecule-1 expression by crocetin contributes to attenuation of atherosclerosis in hypercholesterolemic rabbits. Bioch Pharmacol 2005; 70: 1192-1199

49 Grisolia S. Letter: Hypoxia, saffron, and cardiovascular disease. Lancet 1974; $2:$ 41-42

50 Kamalipour M, Akhondzadeh S. Cardiovascular Effects of Saffron: An Evidence-Based Review. J Teh Univ Heart Cent 2011; 6: 59-61

51 Verma SK, Bordia A. Antioxidant property of Saffron in man. Indian J Med Sci 1998; 52: 205 
52 Mancuso C, Siciliano R, Barone E et al. Pharmacologists and Alzheimer disease therapy: to boldly go where no scientist has gone before. Exp Opin Investig Drugs 2011; 20: 1243-1261

53 Reitz C, Brayne C, Mayeux R. Epidemiology of Alzheimer disease. Nat Rev Neurol 2011; 7: 137-152

54 Howes MJ, Perry E. The role of phytochemicals in the treatment and prevention of dementia. Drugs Aging 2011; 28: 439-468

55 Ebrahim-Habibi MB, Amininasab M, Ebrahim-Habibi A et al. Fibrillation of alpha-lactalbumin: effect of crocin and safranal, two natural small molecules from Crocus sativus. Biopolym 2010; 93: 854-865

56 Hosseinzadeh H, Sadeghnia HR. Safranal, a constituent of Crocus sativus (saffron), attenuated cerebral ischemia induced oxidative damage in rat hippocampus. J Pharm Pharm Sci 2005; 8: 394-399

57 Papandreou MA, Kanakis CD, Polissiou MG et al. Inhibitory activity on amyloid-beta aggregation and antioxidant properties of Crocus sativus stigmas extract and its crocin constituents. J Agric Food Chem 2006; 54: $8762-8768$

58 Shams J, Hedayati $M$, Asefi $F$ et al. Water extract of saffron (Crocus sativus) increases brain dopamine and glutamate concentration in the rat. Eur Neuropsychopharmacol 2010; 20: S353

59 Abe K, Sugiura M, Yamaguchi S et al. Saffron extract prevents acetaldehyde-induced inhibition of long-term potentiation in the rat dentate gyrus in vivo. Brain Res 1999; 851: 287-289

60 Akhondzadeh S, Fallah-Pour H, Afkham $\mathrm{K}$ et al. Comparison of Crocus sativus L. and imipramine in the treatment of mild to moderate depression: a pilot double-blind randomized trial [ISRCTN45683816]. BMC Complement Altern Med 2004; 4: 12

61 Hosseinzadeh H, Karimi G, Niapoor M. Antidepressant effect of Crocus sativus L. extracts and their constituents, Crocin and safranal, in mice. In: Fernández J-A, Abdullaev F (eds.). first International Symposium on Saffron Biology and Biotechnology 2004. Albacete, Spain: 2004

62 Noorbala AA, Akhondzadeh S, Tahmacebi-Pour N et al. Hydro-alcoholic extract of Crocus sativus L. versus fluoxetine in the treatment of mild to moderate depression: a double-blind, randomized pilot trial. J Ethnopharmacol 2005; 97: 281-284

63 Hosseinzadeh $H$, Motamedshariaty $V$, Hadizadeh F. Antidepressant effect of kempferol, a constituent of saffron (Crocus sativus) petal, in mice and rat. Pharmacologyonline 2007; 2: 367-370

64 Karimi GR, Hosseinzadeh H, Khaleghpanah P. Study of antidepressant effect of aqueous and ethanolic of Crocus sativus in mice. IJBMS 2001; 4: $11-15$

65 Hosseinzadeh H, Noraei NB. Anxiolytic and hypnotic effect of Crocus sativus aqueous extract and its constituents, crocin and safranal, in mice. Phytother Res 2009; 23: 768-774

66 Akhondzadeh Basti A, Moshiri E, Noorbala AA et al. Comparison of petal of Crocus sativus L. and fluoxetine in the treatment of depressed outpatients: a pilot double-blind randomized trial. Prog Neuropsychopharmacol Biol Psychiatry 2007; 31: 439-442

67 Burke MJ, Preskorn SH. Standard antidepressant pharmacotherapy for the acute treatment of mood disorders. In: Bloom EF, Kupfer DJ (ed.). Psychopharmacology $-4^{\text {th }}$ Generation of Progress. New York: Raven Press, 1995

68 Sarris J, Panossian A, Schweitzer I et al. Herbal medicine for depression, anxiety and insomnia: a review of psychopharmacology and clinical evidence. Eur Neuropsychopharmacol 2011; 21: 841-860

69 Agha-Hosseini M, Kashani L, Aleyaseen A et al. Crocus sativus L. (saffron) in the treatment of premenstrual syndrome: a double-blind, randomised and placebo-controlled trial. Bjog 2008; 115: 515-519

70 Masinaei Nezhad N, Abdullahi Mohammad AQ, Hashemi Bonjar ZS et al. Effect of Crocus sativus L. (Saffron) on depression among students of zabol faculty of medical sciences 2005. J Neurol Sci 2005; 238 (Supplement 1): (Abstracts of the XVIII ${ }^{\text {th }}$ World Congress of Neurology) S1-S570

71 Shemshian M, Sadeghi A, Kermani $T$ et al. Saffron (Crocus sativus) in the treatment of anxiety and depression: a double-blind, randomized and placebo-controlled trial. Clin Biochem 2011; 44: S118
72 Gomez-Cabrera MC, Vina J, Ji LL. Interplay of oxidants and antioxidants during exercise: implications for muscle health. Phys Sportsmed 2009; 37: 116-123

73 Reid MB. Free radicals and muscle fatigue: Of ROS, canaries, and the IOC. Free Radic Biol Med 2008; 44: 169-179

74 Hosseinzadeh $H$, Modaghegh MH, Saffari Z. Crocus sativus L. (Saffron) extract and its active constituents (crocin and safranal) on ischemiareperfusion in rat skeletal muscle. Evid Based Complement Alternat Med 2009; 6: 343-350

75 Mizuma H, Tanaka M, Nozaki S et al. Daily oral administration of crocetin attenuates physical fatigue in human subjects. Nutr Res 2009; 29: $145-150$

76 Hosseinzadeh $H$, Ziaee T, Sadeghi A. The effect of saffron, Crocus sativus stigma, extract and its constituents, safranal and crocin on sexual behaviors in normal male rats. Phytomedicine 2008; 15: 491-495

77 Shamsa A, Hosseinzadeh H, Molaei M et al. Evaluation of Crocus sativus L. (saffron) on male erectile dysfunction: a pilot study. Phytomedicine 2009; 16: 690-693

78 Safarinejad MR, Shafiei N, Safarinejad S. An open label, randomized fixed-dose, crossover study comparing efficacy and safety of sildenafil citrate and saffron (Crocus sativus Linn.) for treating erectile dysfunction in men naive to treatment. Int J Impot Res 2010; 22: 240-250

79 Safarinejad MR, Shafiei N, Safarinejad S. A prospective double-blind randomized placebo-controlled study of the effect of saffron (Crocus sativus Linn.) on semen parameters and seminal plasma antioxidant capacity in infertile men with idiopathic oligoasthenoteratozoospermia. Phytother Res 2011; 25: 508-516

80 Sultana $A$, ur Rahman $K$, Nagaraj RB. Conception in unilateral right tubal blockage with herbomineral formulations: a case report. J Altern Complement Med 2011; 17: 557-561

81 Dante G, Facchinetti F. Herbal treatments for alleviating premenstrual symptoms: a systematic review. J Psychosom Obstet Gynaecol 2011; 32: $42-51$

82 Coco AS. Primary dysmenorrhea. Am Fam Physician 1999; 60: 489-496

83 Nahid K, Fariborz M, Ataolah G et al. The effect of an Iranian herbal drug on primary dysmenorrhea: a clinical controlled trial. J Midwifery Womens Health 2009; 54: 401-404

84 Fukui H, Toyoshima K, Komaki R. Psychological and neuroendocrinological effects of odor of saffron (Crocus sativus). Phytomedicine 2011; 18: 726-730

85 Wallis DJ, Hetherington MM. Emotions and eating. Self-reported and experimentally induced changes in food intake under stress. Appetite 2009; 52: 355-362

86 Feo F, Martinez J, Martinez A et al. Occupational allergy in saffron workers. Allergy 1997; 52: 633-641

87 Varasteh A, Rahim Zadeh M, Farid Hosseini $R$ et al. Determination of saffron (Crocus sativus) allergenicity. IJBMS 2000; 3: 33-37

88 Kianbakht S, Ghazavi A. Immunomodulatory effects of saffron: a randomized double-blind placebo-controlled clinical trial. Phytother Res 2011; 25: 1801-1805

89 Abdullaev F. Biological properties and medicinal use of saffron (Crocus sativus L.). Acta Hort (ISHS) 2007; 739: 339-345

90 Konoshima T, Takasaki M, Tokuda $\mathrm{H}$ et al. Crocin and crocetin derivatives inhibit skin tumour promotion in mice. Phytother Res 1998; 12: 400-404

91 Golmohammadzadeh S, Jaafari MR, Hosseinzadeh H. Does Saffron have antisolar and moisturizing effects? IJPR 2010; 9: 133-140

92 Vyas LK, Tapar KK, Nema RK. Study of Crocus sativus as complexion promoter in skin care. IJPCR 2010; 2: 76-79

93 Hosseinzadeh $H$, Abootorabi A, Sadeghnia HR. Protective effect of Crocus sativus stigma extract and crocin (trans-crocin 4) on methyl methanesulfonate-induced DNA damage in mice organs. DNA Cell Biol 2008; 27: 657-664

94 Chatterjee S, Datta RN, Bhattacharyya D et al. Emollient and antipruritic effect of Itch cream in dermatological disorders: A randomized controlled trial. Indian J Pharmacol 2005; 37: 253-254 